\title{
Homeostatic version of the formation of human capital: ecological aspect
}

\author{
Radiy Ibragimov* \\ Katanov Khakass State University, Abakan, Russia
}

\begin{abstract}
Now it is found that under the capitalized qualities of a person, not only high-tech competencies can be understood. This capital does not exist outside time and space; Its implementation responds to specific social queries. For example, with the current demographic dynamics, the territory of a huge country through a couple of generations will be unnecessary. The article substantiates the thesis that the post-industrial model of the history is an optional development line. In conditions of social entropy, the return to homeostatic equilibrium with an ecological environment is both the most humanistic, and the most clearly predicted, and the least costly of the future scenarios. The consideration of the inevitability of homeostasis, in turn, leads to the need to interpret the concept of «human capital», which will allow the typical carrier of such capital to be the most successful in the new socio-ecological situation.
\end{abstract}

\section{Introduction}

At first glance, there is no direct relationship between the patterns of human capital generation and functioning the natural and even anthropogenic ecosystems. It arises when a high-performance engineering intelligence is set, and does not naturally mature, the task of designing or adjusting processes in geobiocenoses of various scales.

In a sense, two problems, human capital and ecology, in their classical understanding are even alien to each other. In absolute terms, the highly developed human capital of the Kuznets-Becker-Schultz paradigm lives mainly in the ultra-urban environment, is much less common in industrial centers and almost never occurs in rural areas. Many researchers put the country level of human capital development in direct dependence on the proportion of the urban population $[1,104]$. In this classical and narrow understanding of human capital, many regions of Russia, especially Siberia and the Far East, are a dull spectacle, to put it more academically, they are depressive. Not only is the share of the rural population almost equal to the share of the urban population in Khakassia, Yakutia, Tyva, Buryatia, in the Chita and Irkutsk regions, in the north and southeast of the Krasnoyarsk Territory, this population is also scattered over vast territories.

However, to date, the discourse "Human Capital" has undergone many substantive corrections, additions and semantic layering. [2] It was found that capitalized qualities can be understood not only as high-tech or "digital" competencies, but also sports or aesthetic

* Corresponding author: dison1@mail.ru 
talents. Moreover, this discourse has long been tested in social practice, where the range of interpretations and applications is even wider. For example, it is not a secret for anyone that in Russia the "parent capital" has become a specific concretization of human capital; that is, female fertility was designated the capitalized "talent".

In these conditions, it is quite fair to raise the question of practical concretization and localization of the concept of "human capital". This capital does not exist outside of time and space; it, its production and sales respond to specific social needs. The same project of parental capital did not appear out of nowhere, but as a response (belated!) to specifically Russian problems that are not typical of Western Europe or Africa. Namely: with the current demographic dynamics, the territory of a huge country will turn out to be unpopulated in a couple of generations.

However, even if the program of demographic activation turns out to be successful, it does not automatically solve all the problems associated with use of natural resources and nature conservation. The situation with forest fires in recent years shows that even such a rare population manages to inflict catastrophes on a federal and even planetary scale. In other words, in remote Siberian and Far Eastern provinces, it is necessary not only to preserve the population of Russians; it is also necessary to install certain "human qualities" in it. The ecological culture of the population serves here as a very informative social marker.

\section{Materials and methods}

Our study was carried out within the framework of the study project "The Problem of Effective Use of Human Capital: Regional Dimension". Its methodological feature is approbation of a predominantly macroeconomic concept of human capital by means of empirical sociology. [3]

This explains the features of the axiomatic basis of the study, namely, the emphasis and concentration of our search activity on the motivational component in the structure of human capital, which allows us to make the subject of study not only traditional, but also alternative scenarios for the embodiment of human capital.

Implementation of this program segment was a series of formalized interviews with respondents who are hypothetically carriers of excess motivational energy, the so-called "passionaries". Founding, identification from the methodological and technical point of view was not particularly difficult, since the passionary always stands out against the average statistical social background. Therefore, the "snowball" method was used for the sample, as a result of which 168 interviews were obtained, in the guide of which such meaningful parameters as attitude to work, everyday life, social microenvironment, and time management were revealed. Attitudes towards environmental problems were not specifically revealed, however, almost all respondents from rural areas and a fairly large percentage of respondents from urban areas (113 texts in total) spoke about certain environmental problems in the region. Considering the fact that these were economically and socially active citizens, we considered it necessary to form a special, "ecological" section in the general program of the study project.

In addition, in this project, a large methodological role is assigned to the analysis of documents of various forms and statuses. This shall include statistical reviews, filing of local newspapers of different years (Khakassia, Abakan), materials from electronic media, local scientific and business forums (for example, Big Business held on August 21, 2019 (https://r-19.ru/news/ekonomika/91455/)). It can be seen from the materials that environmental issues practically did not leave the agenda of public discussion.

The study of models of human capital formation in the conditions of the Khakassia region and the south of the Krasnoyarsk Territory allows, in our opinion, application of the 
extrapolation method both to other regions of the Russian Federation and to the model of their evolution in time, to the "scheme" of their historical development.

\section{Results and discussion}

So, location of the empirical study is the Republic of Khakassia and the south of the Krasnoyarsk Territory. This region, despite the current administrative division, represents a geological, ecological, economic and cultural unity. In the language of geology and ecology, this unity is called the Khakass-Minusinsk Basin. It is a kind of geological "bowl" bordered on all sides by the spurs of the Sayan Mountains. The basin area is more than 130 thousand square kilometers. The population is about 660,000 people.

Historians believe that during periods of economic and political heyday (for example, during the times of Dinling-go or the Kyrgyz Kaganate), the population was kept near this mark. [4, pp. 28, 39]. For our study, these figures are one of the key points, since they fix the demographic possibilities of the enclosing landscape. Indeed, the statistics of recent decades also show that the threshold of population capacity in the region has not fundamentally changed.

The demographic dynamics shown above is suggestive. Its mechanisms in relation to the eras of antiquity and the Middle Ages are well studied. The social system of the Dinling-go and the Kyrgyz Kaganate rested on the extensive agricultural and nomadic use of the landscape, and the relatively high birth rate was compensated for by child mortality and the death of young people in the constant internal and external conflicts of those times.

It would seem that the current situation is fundamentally different. Child mortality and war are long excluded as demographic factors. The share of the rural population in the region is close to $50 \%$; there are no large cities at all. The only city whose population exceeds 100,000 is the capital of Khakassia, Abakan $(180,000)$; the population of 3 more cities (Minusinsk, Chernogorsk, Sayanogorsk) fluctuates around 50 thousand. Therefore, the factor of "urban utilization of the population", which is characteristic of cities with a population of one million, does not work here either.

Meanwhile, as mentioned above, there is still no population growth in the region. [5] The most frequently cited reason - the alcoholization of the population, especially the rural population - certainly takes place. In our interviews, the word "soldering" was used to describe problems 48 times, the names of alcoholic beverages as a source of evil ("vodka", "vodyara", "spirtyaga") - 77. However, this factor is not a comprehensive explanation.

Inclusion of the human capital factor in the framework adds more detail to the outlined diagram. The inflow and outflow of the population in the region in the last 20 years has been about 5 thousand people per year. Mostly school graduates leave, whose USE results allow them to apply for places in universities in Krasnoyarsk, Novosibirsk, Tomsk, St. Petersburg and Moscow. These are promising carriers of human capital, the "production" of which is quite well established by the school education system in the region. As well as in the whole country. [6;7] Our expert from the Ministry of Education and Science of the RH reported (in fact, boasted) that with an annual release of approx. 1,800 only Moscow universities enroll "at least two dozen" of graduates.

Another reserve of outflow, but much less "full-flowing", is labor migration in order to find more promising jobs.

The inflow into the region is formed mainly from two social groups - 1) residents of the northern territories (Norilsk residents) migrating to settle in a more favorable climate than before, and 2) residents of the Central Asian republics who come in search of work.

It is easy to conclude that the dynamics of human capital in the region is most accurately reflected by the terms "erosion" and "homeostasis". Here we need an argumentative inclusion designed to clarify our position. In the structure of human capital, 
we include a component that is explicitly contained even in the classical theory - namely, the social and energy potential of the individual and the population, which is often called "passionarity". This means that the knowledge, skills and abilities that bring added value to investors do not mean much in and of themselves. Their owner must show increased motivation, activity, ambition in order to bring their knowledge and talents to the stage of productive implementation.

With this argument in mind, from our provincial region (as well as from many others), a social cohort of bearers of not only competencies, but also energy is gradually being washed out. The same is observed in relation to many other regions [8]. The depletion of passionarity, in turn, gives rise to a state of homeostasis - economic, political, demographic and environmental. [9].

Demographic stagnation has already been discussed above. More details shall be said about similar processes in the economy. Let's start with the next news item. Now, literally before our eyes, a spontaneous political and economic experiment is unfolding. Russian Defense Minister S.K. Shoigu, a native of neighboring Tuva, recently announced the idea of creating "on the border of the Krasnoyarsk Territory and Khakassia" a million-plus city called Electrograd on the basis of a powerful industrial cluster also planned to be created. (https://svpressa.ru/economy/article/308314/, date of last visit 09/09/21.) Where to get an additional million in the demographically depressive outback, not just residents, but city dwellers? Where do several high-tech enterprises of federal and even global scale come from there?

As usual, there are two possible answers to the questions posed - optimistic and pessimistic, "Pro" and "Contra". The optimistic answer, as we see it, appeals to two arguments -1) money and 2) personality.

Financing is the easiest: a country that can build Mordovia-Arena stadiums for 17 billion rubles and Gazprom-Arena for 50 billion rubles can easily afford the construction of a dozen factories in the Khakass steppes.

Item 2 shall be articulated in more detail. Personally, Sergei Kuzhugetovich is a vivid example of the implementation of human capital. However, considering the fact that at a certain moment in the embodiment of the life scenario, he, as a manager, with his qualities and passion, has outgrown the scale of the region. Being, without any doubt, not indifferent to the fate and condition of his small homeland, he looks at these fate and condition through the eyes of a productive passionate who has migrated to a more promising federal center. A passionary is guided by the principle "perspective is more real than reality".

A passionary equipped with a financial resource is, of course, a great power. There are many examples in history when the most fantastic projects were implemented without such a resource. However, this is the problem: the theory of passionarity speaks the language of synergetics, and synergetics does not have predictive power.

Therefore, a pessimistic scenario, "Contra". The same theory asserts that the entire content of the historical process is utilization of passionarity. Homeostasis is an inevitable outcome of any social evolution. The settings of a social system, in which there is only enough energy to maintain the present state, are just enough to get rid of any "growth points" that require excessive efforts. Demography is the most striking example here. If women do not want to give birth even under threat (-) of payments of maternity capital, it means that the population is not even in homeostasis, but in the stage of decay.

This is evident even in regions with a predominantly rural population, such as ours. Since 2010, monitoring the attitude of young girls to the prospects of childbearing shows that 2 or more children are going to give birth to no more than $20 \%$, and vice versa, twice as many respondents do not consider such a prospect at all.

The slide of the local community into homeostasis is no less evident in the sphere of economics. The peak of economic development here was the construction of the Sayano- 
Shushenskaya hydroelectric power station and the Sayan Aluminum Plant (SaAZ). In 1970$80 \mathrm{~s}$, a project for the industrialization of the region with the same geolocation as in the project of S.K. Shoigu, provided for commissioning of 12 more large advanced productions. However, then perestroika (restructuring) and post-perestroika began, and the frames of the unfinished workshops still adorn the right bank of Yenisei river.

Attempts to intensify the industrial life of the region did not end there. In the 2000s, against the background of the extinction of the city-forming enterprise AbakanVagonMash on the initiative of O.V. Deripaska (also a passionate, originally from neighboring Krasnoyarsk, his business empire was born in Khakassia) began to actively discuss the issue of building a polysilicon enterprise in the city of Abakan. Arguments "Pro" were voiced in his interview by the Director General of Russian Silicon LLC A. Suponenko: "Silicon production is a very energy-intensive process, and Khakassia has the necessary energy resources. In addition, in Abakan there is a convenient industrial site that is not used in any way, there are roads, communications, there are people who are able to build such a plant and in the future will be able to work on it". (https://marketelectro.ru/content/abakanskiy-polikremniy-ot-sluhov-i-domyslov-k-istine, date of last visit 09/09/21).

However, it was the "people", and precisely for environmental reasons, who actively opposed this project, and in 2010 the local authorities were forced to put an end to this project.

The irony of the situation is that, having won the ecological war against high-tech industrialization, the population of the RK lost it on the front of the struggle against the economically, energetically and technologically unpromising and no less environmentally hazardous coal industrialization. Until the 2000 s coal in Khakassia was mined by the mine method; however, over the past 20 years, as many as 8 new open pit coal mining companies have been formed. It is not even worth commenting on how detrimental coal mines affect the ecological situation, which is aggravated by the fact that coal mining is carried out in the steppe ecosystem, which is extremely fragile. Thickness of humus here is on average $10 \mathrm{~cm}$; its growth rate does not exceed $1 \mathrm{~cm}$ per 100 years.

The population and spontaneously formed initiative groups are waging a continuous struggle against the coal industrialization disfiguring the nature of the Khakass-Minusinsk Basin, but in vain. The large coal business turned out to be more influential even than the local authorities, since only 1 out of 8 coal companies (Mayrykhsky Razrez LLC) is a local tax resident. The rest deduct taxes either in Moscow or abroad in general. That is, the republic does not even have economic benefits from the environmentally hazardous activities of economic entities.

Since the shortfall in taxes occurs not only on the part of coal companies, but also on the part of almost all major regional players, the population's discontent also extends to local legislative and executive authorities. This also has a direct bearing on the efficiency of using human capital. Thus, Khakassia became the second region in which the population in 2018 elections refused to trust the acting governor M.V. Razvozhaev, who was appointed from the personnel reserve of the President, proved himself well in a few months in office and is showing himself even better at the moment as governor of Sevastopol. Instead, the population stubbornly voted for the local young communist V. Konovalov, whose team brought the republic to the last places in the rating of economic well-being.

Thus, not only in the economy, but also in politics, in the civil service, the efficiency of using human capital is most accurately characterized by the concept of a "problem". Its manifestation was the population's choice in favor of the Communist Party, the desire for innovation, or, conversely, the manifestation of ideological fatigue, i.e. homeostasis? The answer is obvious, although in the desire to "do everything as it once was" the population of the region turned out to be more original than other regions. 
So, signs of homeostasis take place in various spheres of social life. From an ecological point of view, homeostasis is a state where a population is in equilibrium with its environment. That is, it reproduces indefinitely the same load on the landscape, the same livestock, the same management methods. It is not difficult to see in this model the signs of a pre-industrial society.

And vice versa, all revolutions, both political, economic and cultural, were initiated by "consortia" of passionaries who received certain resources of influence. Industrial and, further, post-industrial societies are, among other things, the result of the passionate enthusiasm of communities and social cohorts of promoters.

The environmental consequences of such explosive changes are almost always catastrophic. For the inhabitants of our region, this pattern is illustrated by the native steppe cut by coal quarries.

However, for Khakassia with southern Krasnoyar, and for many similar territories of Russia, the socio-ecological situation is somewhat different than, for example, for Western Europe. There, socio-economic changes have gone so far that the city has become an ersatz substitute for "natural" nature. Adaptation to the environment is concretized in the concept of "urban environment". It has been noticed, for example, that populations of hereditary inhabitants of megalopolises are always less energetic than newcomers ("brand-new arrivals"). That is, even falling into "urban homeostasis" [10] acquires irreversible socioeconomic forms, which, in turn, creates the illusion of the irreversibility of the historical process, the vector of movement from a pre-industrial society to a post-industrial one.

In remote provinces of Russia with its large undeveloped and semi-developed territories, the loss of social energy (passionarity) by the population can and often proceeds according to an alternative scenario. More precisely, the main one, since according to most parameters, economic management in regions like ours, for the majority of the population, means a return to the original cultural, historical and economic positions - to "preindustrialism", and not a breakthrough to something new.

The most important argument (both theoretical and practical) is the "cost of homeostasis". Any revolution, whether industrial or post-industrial, requires increased costs, and at the same time generates "artificial natural selection", rejecting, making more and more people unable to enjoy the benefits of post-industrial civilization. The fourth industrial revolution threatens to make the issue of impending unemployment unsolvable, in principle. [11] The "cheapest" solution may be the "traditional homeostatic" scenario. Recognition of this alternative is already taking place, for example, in relation to "pandemic migration". [12]

However, this automatically raises the question of the main typological features of the participants in this scenario, of a new reformulation of the concept of human capital. The coming urbanist lumpen-proletarian is least of all suited for "humanization" of the expanses of Siberia and the Far East.

\section{Conclusion}

Consideration of the problems of generation and effective use of human capital in remote Russian provinces through the prism of an ecological approach leads to a number of conclusions that are not so obvious within the framework of economic determinism or various sociological paradigms.

The most ambitious conclusion, or rather a hypothesis awaiting further discussion, is the assumption that the three-part model of history "pre-industrial, industrial, post-industrial society" is not the main, but an optional line of development. In the context of social entropy, signs of which can be found both in depressed provincial regions and in the most ultra-urban clusters, a return to homeostatic equilibrium with the ecological environment is 
simultaneously the most humanistic, and the most clearly predictable, and the least costly of the future scenarios.

The statement of the inevitability of homeostasis, in turn, leads to the need to interpret the concept of "human capital", which will allow the typical bearer of such capital to be most successful in a new socio-ecological situation. Simply said, one shall seriously think about whether German Sterligov is an eccentric exception to the rule or a social archetype of the personality of the future.

\section{Acknowledgements}

The reported study was funded by RFBR according to the research project № 19-01100365 .

\section{References}

1. D. Didenko. World of Russia, 30(3), 100 (2021)

2. N. Tikhonova, A. Karavay, Sociological research, 5, 84 (2018)

3. R. Ibrahimov, E3S Web of Conferences, 258, 10003, 1 (2021)

4. History of Khakassia from ancient times until 1917 (1993)

5. O. Lushnikova. Sociological research, 10, 63 (2020)

6. E. Denisova-Schmidt, World of Russiaю, 30(3), 174 (2021)

7. G. Zborovsky, P. Ambarova, World of Russia, 30(1), 88 (2021)

8. J. Toshchenko, P. Velikij, World of Russia, 27(1), 7 (2018)

9. A. A. Posanenko, World of Russia, 27(4), 31 (2018)

10. O. Borisova, I. Pavlutkin, World of Russia, 28(4), 128 (2019)

11. K. Schwab, T. Malleret, COVID-19: The great reset (2020)

12. N. Pokrovsky, A. Makshanchikova, E. Nikishin, Sociological research, 12 (2020) 